University of Nebraska - Lincoln

DigitalCommons@University of Nebraska - Lincoln

Agronomy \& Horticulture -- Faculty Publications

Agronomy and Horticulture Department

2004

\title{
Factors affecting the realized niche of common sunflower (Helianthus annuus) in ridge-tillage corn
}

\author{
Michael G. Burton \\ North Carolina State University \\ David A. Mortensen \\ Pennsylvania State University \\ David B. Marx \\ University of Nebraska-Lincoln, david.marx@unl.edu \\ John L. Lindquist \\ University of Nebraska-Lincoln, jlindquist1@unl.edu
}

Follow this and additional works at: https://digitalcommons.unl.edu/agronomyfacpub

Part of the Plant Sciences Commons

Burton, Michael G.; Mortensen, David A.; Marx, David B.; and Lindquist, John L., "Factors affecting the realized niche of common sunflower (Helianthus annuus) in ridge-tillage corn" (2004). Agronomy \& Horticulture -- Faculty Publications. 413.

https://digitalcommons.unl.edu/agronomyfacpub/413

This Article is brought to you for free and open access by the Agronomy and Horticulture Department at DigitalCommons@University of Nebraska - Lincoln. It has been accepted for inclusion in Agronomy \& Horticulture -Faculty Publications by an authorized administrator of DigitalCommons@University of Nebraska - Lincoln. 


\section{Factors affecting the realized niche of common sunflower (Helianthus annuus) in ridge-tillage corn}

\section{Michael G. Burton}

Corresponding author. Department of Crop Science, North Carolina State University, Raleigh, NC

27695-7620; mike_burton@ncsu.edu

David A. Mortensen

Department of Crop and Soil Sciences, Pennsylvania State University, University Park, PA 16802-3504

David B. Marx

Department of Statistics, University of NebraskaLincoln, Lincoln, NE 68583-0712

John L. Lindquist

Department of Agronomy and Horticulture, University of Nebraska-Lincoln, Lincoln, NE 68583-0915

\begin{abstract}
Because soil characteristics and weed densities vary within agricultural landscapes, determining which subfield areas are most favorable to weed species may aid in their management. Field and greenhouse studies were conducted to determine whether subfield environments characterized by higher soil organic carbon (SOC), or ridge vs. furrow microsites, affect common sunflower seed germination after winter burial, seedling emergence, or the control afforded by a preemergence herbicide in a ridgetillage corn production system. Among seeds buried in situ during winter months and germinated in the laboratory, no differences in common sunflower seed germination or mortality were detected between high-SOC (1.8\% mean) and low-SOC (1.1\% mean) locations. However, seeds buried at 5-cm depth had about $40 \%$ laboratory germination compared with about $10 \%$ for seeds stratified on the soil surface or under crop residues. In field emergence and survival experiments, the SOC mainplot effect indicated $25 \%$ greater seedling survival in high- than in low-SOC locations. In the absence of herbicide, both emergence and survival were $\geq 35 \%$ greater in the ridge than in the furrow microsite, and seedling survival was $48 \%$ greater in high- vs. low-SOC furrow environments. However, common sunflower seedling survival was similar between herbicide-treated high- and low-SOC ridges. Greenhouse studies indicated a 13 to $24 \%$ increase in common sunflower seedling biomass per $1 \%$ increase in SOC under three atrazine doses. Altered or additional weed management tactics should be considered for common sunflower in high-SOC environments to offset the greater potential for seedling survival and growth.
\end{abstract}

Nomenclature: Atrazine; common sunflower, Helianthus annuus L. HELAN; corn, Zea mays L.

Key words: Atrazine, soil heterogeneity, soil organic matter, weed population dynamics.
The effects of soil and landscape characteristics on the persistence and growth of a weed species have received increased attention in recent years. Interest in plant population dynamics and ecophysiology has historically promulgated such niche delineation investigation (Harper 1977; MuellerDombois and Sims 1966; Pickett and Bazzaz 1976) at various scales (Hartgerink and Bazzaz 1984). However, the advent and affordability of site-specific management technologies (i.e., georeferencing and precision farming) has further stimulated interest in understanding why weeds occur where they do, why different species exhibit different degrees of patchiness, and why weeds persist in some locations despite intense efforts to manage or eradicate them. Many integrated weed management (IWM) specialists believe that through a better understanding of weed population ecology, practitioners will be better able to manage weed pests (Cousens and Mortimer 1995; Mortensen et al. 2000).

Evidence of weed associations with physiographic (Johnson et al. 1999) and soil characteristics in agricultural (Andreasen et al. 1991; Dale et al. 1992; Dieleman et al. 2000a, 2000b; Medlin et al. 2001) and other highly disturbed environments (Dale 1964) exists. However, previous work conducted using coarse-scale grid $(30 \mathrm{~m})$ sampling resulted in poor correlation of weeds to soil characteristics across years (Medlin et al. 2001). In addition, several investigators have examined demographic factors contributing to weed population dynamics in intensively managed agroecosystems
(Fernandez-Quintanilla et al. 1987; Lindquist et al. 1995; Naylor 1972), but there are limited data on the effects of heterogeneity in soil and landscape characteristics on weed population ecology. Harper's (1977) population model allows us to consider weed phenology as a series of generalized stages, all of which should be examined in evaluating the effect of niche characteristics on population dynamics. The present work addresses the effects of the environment and management on critical stages of plant growth, beginning with seed entry into the seed bank (i.e., the interface of Harper's Stage IV and Stage I). It further examines the effects of environmental "sieves," i.e., soil organic carbon (SOC) and soil-applied herbicide on the emergence and seedling phase of plant growth (Stage II). Burton (2000) examined the remaining life history stages (from juvenile through reproductive stages) of common sunflower. Such data are essential for weed population modeling efforts (Cousens and Woolcock 1997; Doyle 1991; Gonzalez-Andujar and Fernandez-Quintanilla 1991) and for directing long-term weed management.

Dispersed seeds in tilled fields are initially deposited on the soil surface, within or under residues, or are buried at various depths by erosion, animal activity, or in soil cracks. Some of these seeds are redispersed to other locations by wind and water (Burton and Mortensen 2002) or tillage (Maxwell and Ghersa 1992; Rew and Cussans 1997). Depending on their dormancy status, seeds that survive in the 
various seed bank locations might have the opportunity to germinate in the spring after dispersal.

The ridge-tillage system, which is widely used in irrigated cropland in the Platte River valley of Nebraska (and elsewhere), has been observed to affect weed seed density and distribution. Although the total density of weed seeds increased with ridge tillage compared with conventional tillage, fewer seeds were observed in the truncated ridges of crop rows (Forcella and Lindstrom 1988a, 1988b; Klein et al. 1996; Wicks and Somerhalder 1971). At harvest there is typically 10 - to $20-\mathrm{cm}$ vertical relief between contiguous furrows and ridges. Consequently, most weed seeds originally dispersed to the intact ridge are moved into the furrow by erosion, and some are buried in soil cracks. Crop residues fall into the furrow spaces during crop harvest. If weed seeds were uniformly dispersed before or during harvest, more seeds would be expected to land in the furrow space because of the convex shape of the ridge. Cold, moist stratification has been observed to reduce common sunflower seed dormancy in the laboratory (Maguire and Overland 1959). The disposition of weed seedrain on the soil surface, among plant residues, or buried in soil during winter months may result in a range of environments that reduce the fraction of dormant weed seeds through a natural process of stratification.

Some soil chemical and physical gradients affecting plant growth include soil fertility, $\mathrm{pH}$, depth, texture, moisture, and organic carbon. Austin and Austin (1980) observed that several grass species produced maximum shoot growth at similar soil fertility levels when grown in monoculture. In competition with other species, however, peak growth for each species occurred at a different fertility level. Hoveland et al. (1976) demonstrated that relative yield of several weedy grasses and forbs in monoculture was reduced when soil test $\mathrm{P}$ or K levels fell to 22 or $164 \mathrm{~kg} \mathrm{ha}^{-1}$, respectively. Depth and $\mathrm{pH}$ of soil were correlated to the distribution of several species colonizing a nonarable slope in southeastern Sweden (Tyler 1996). Seedling recruitment in Colorado grasslands increased with silt and clay content after disturbance (Coffin and Lauenroth 1994). Pennsylvania smartweed (Polygonum pensylvanicum L.) reproduced at all points along a soil moisture gradient, whereas co-occurring velvetleaf (Abutilon theophrasti) succeeded in reproducing only in the drier portion of the moisture gradient (Pickett and Bazzaz 1976). Soil heterogeneity in each of the above characteristics could be important in determining the realized niche for a given plant species. The degree to which weedy species depend on a particular resource (i.e., degree of specialization), or can tolerate a less-favorable resource state, will contribute to its success and distribution in row-crop agroecosystems.

Within-field heterogeneity in SOC is of particular interest as a soil characteristic because areas with high SOC may be more favorable habitats where soil-applied herbicides are frequently used. Williams et al. (2001) observed correlations of velvetleaf seedling growth and SOC or sand content (Pearson correlation coefficients of 0.63 and -0.76 , respectively) when soil was uniformly treated with isoxaflutole. Through canonical correlation analysis, Dale et al. (1992), Dieleman et al. (2000a, 2000b), and Medlin et al. (2001) identified weed associations with SOC or soil type. Dieleman et al. (2000b) observed correlations of velvetleaf, common sunflower, and hemp dogbane (Apocynum cannibinum), within subfield areas with high SOC concentration in the present study site.

Because weed management in corn often relies on the success of soil-applied herbicides as a component of an IWM plan, the efficacy of chemical control during the emergence-seedling phase of plant growth plays a critical role in weed management. In the north-central region of the United States, uniform rates of herbicide are routinely applied across fields of $>60$ ha. However, soils within these (or smaller) areas (Cambardella et al. 1994; Novak et al. 1997) may vary in characteristics (e.g., SOC, \%clay, pH) that affect sorption or activity of soil-applied herbicides, thereby influencing herbicide efficacy (Blumhorst et al. 1990; Sheets et al. 1962). Efficacy becomes even more important for weed species (such as velvetleaf and common sunflower) that are highly competitive, are prolific seed producers, and demonstrate considerable seed bank longevity. Survival and reproduction of these species, even at seemingly low densities, can still result in economic injury and increasing weed population size (Bauer and Mortensen 1992; Cardina et al. 1995).

The objective of this research was to determine whether subfield environments characterized by higher SOC concentrations (often associated with low landscape position) are more conducive to the survival of common sunflower during seed stratification, seed germination and seedling emergence, or the period of preemergence herbicide control. The approach used also allowed investigation of whether the ridge or furrow microsite was more conducive to common sunflower emergence.

\section{Materials and Methods}

\section{Field Site}

Experiments were established near Shelton, NE, in the Platte River valley. The 64-ha field had a 21-yr continuous corn production history. Before 1993, the site was managed with conventional tillage but has since been managed with ridge tillage. In this continuous corn production system, the corn root crown from the previous season was removed from the ridge by a stalk chopper, and ridges were truncated by a rotary tiller before planting. During these practices, soil from the ridge is mixed and redistributed to the furrow. Maximum vertical relief to the field was $2.5 \mathrm{~m}$, and SOC ranged from 0.6 to $2.8 \%$ (Varvel et al. 1999). Soil types include Blendon loam (Coarse-loamy, mixed, superactive, mesic Pachic Haplustolls) and Hord silt loam (Fine-silty, mixed, mesic Cumulic Haplustolls).

\section{Seed Burial Study}

The influence of stratification and SOC location on the germination and survival of newly dispersed common sunflower seeds was evaluated by establishing seed banks under a range of microsite conditions. Seeds were collected from the soil surface at Havelock, NE, on November 30, 1998 and November 19, 1999 and stored at $5 \mathrm{C}$ until placed in the Shelton field. Fifty seeds that were retained on a $2-\mathrm{mm}$ round-hole sieve were placed in $10-\mathrm{cm}$ square litterbags made of lightweight nylon mesh (1-mm mesh) that were fused twice at the edges with a thermal seam sealer. Litterbags were placed in the field on December 13, 1998 and 
December 19, 1999 and collected on March 18 and 5, respectively, in the following year.

A split-plot experimental design with subsampling was used in this experiment. The main-plot treatment was SOC location within the field (described below). Four locations within the field were selected to obtain two pairs of highand low-SOC locations. One high-low pair was located in the north half of the field, and the other high-low pair was in the south half (north and south locations were separated by $>400 \mathrm{~m}$ ). The split plot included three burial treatments: surface, buried, or residue. In each burial treatment, three litterbags (treated as subsamples in the analysis) were spaced $25 \mathrm{~cm}$ apart within a meter of crop row. Surface litterbags were placed on the soil surface of the ridge and held in place by a $7.5-\mathrm{cm}$-diam steel ring (with three attached stakes). Crop residues (corn stover) and the top 5 $\mathrm{cm}$ of soil were carefully removed from the adjacent meter of furrow. Litterbags were either buried at the $5-\mathrm{cm}$ depth (buried) or placed on top of the soil in the furrow but under the corn crop residue (residue) in the furrow. Residues completely covered the litterbags. These two treatments were paired with one another, and each subsample pair was held in place by a $7.5-\mathrm{cm}$ steel ring. Crop residues were returned to the furrow in a similar distribution as was originally observed. A fourth treatment (no-litterbag) in which seeds were placed directly on the ridge surface in the center of a steel ring was only used in 1998 to test for a litterbag effect.

The day after litterbag collection, seeds were subjected to a rolled-towel germination test, except as noted below. To prevent an observation from becoming too influential on a proportional basis, a subsample was treated as a missing datapoint if fewer than 38 intact seeds (about $75 \%$ of the original number of seeds) were recovered in a subsample. Rolled towels were kept moist in a germination chamber with a 16-h dark period at $15 \mathrm{C}$ and an 8 -h illuminated period at $30 \mathrm{C}$. Each rolled-towel test was evaluated at 14 $\mathrm{d}$ for germinated and dead seeds. Germination was defined as radicle protrusion from the testa. Dead seeds were identified at the end of the germination test (i.e., decaying seeds disintegrated when pressed with a probe). Seeds that did not obviously fall into either category were longitudinally bisected and soaked for $18 \mathrm{~h}$ in $0.1 \%$ tetrazolium chloride at 20 C. Embryos that were unstained, weakly stained, or in which critical structures were weakly stained were classified as nonviable (Anonymous 2000). Dead and nonviable seeds were combined and reported as Dead/NV seeds. Analysis of variance (ANOVA) was used to test for main- and split-plot effects using the MIXED procedure in SAS (Littell et al. 1996). Year was treated as a fixed variable.

\section{Emergence and Seedling Survival-Field Study}

The effects of SOC location, herbicide, and microsite on common sunflower seedling emergence and early-season growth were tested. Twelve plot locations were selected on the basis of landscape position and soil color to represent high- and low-SOC locations, which were paired (six highlow pairs) such that each high-low pair occurred in the same set of crop rows and were not subject to tractor wheel traffic. Each plot consisted of seven crop rows spaced $0.76 \mathrm{~m}$ apart. The center and edge rows served as buffer strips among randomly assigned subplot treatments (untreated control or banded preemergence herbicide). Each subplot consisted of
$1 \mathrm{~m}$ of two neighboring crop rows and between-row spaces. Within each subplot, one common sunflower seed was planted at each $10-\mathrm{cm}$ interval in each of two between-row spaces (furrows) and on both sides of each of two crop rows (ridge), such that 20 seeds were planted in furrows and 40 seeds were planted in ridges in each subplot. Ridge seeds were planted near the crop row to assure that they would be within the herbicide-treated band. Seeds used in this experiment were collected in 1995 from Havelock, NE, and stored dry in plastic bags at -5 C. Seeds (selected as described above) were treated to promote germination by clipping 1 to $2 \mathrm{~mm}$ from the cotyledonary end (1998) or with a 24-h soak in $850 \mathrm{ppm}$ gibberellic acid $\left(\mathrm{GA}_{3}\right)^{1}$, which was dissolved in phosphate-buffered saline $(\mathrm{pH} 7.4)^{2}$ (1999). Weed seed planting was performed $1 \mathrm{~d}$ after crop planting (DACP) using small probes (4-mm diameter) to create holes at a $45^{\circ}$ with a vertical depth of approximately $4 \mathrm{~cm}$. Each hole was gently pressed closed. Within $2 \mathrm{~d}$ after planting common sunflower (3 DACP) and immediately before a rain event in both years, herbicide was applied in a $0.38-\mathrm{m}$ band centered over the crop row. Herbicide-treated subplots received one-half the recommended rate of $2.8 \mathrm{~kg}$ ai ha ${ }^{-1}$ acetochlor and $1.10 \mathrm{~kg}$ ai ha ${ }^{-1}$ atrazine.

The experimental design used SOC level as the main plot, herbicide treatment as the split plot, and ridge vs. furrow microsite as the split-split plot. Emergence observations were made twice weekly. Total emergence and survival were recorded up to the date of mechanical cultivation (30 DACP). Although emergence data collection was not affected, data on the effect of herbicide (i.e., seedling survival) were not included for two sites because of damage caused by feeding of thirteen-lined groundsquirrel (Spermophilus tridecemlineatus Mitchill) on common sunflower seedlings (Virchow and Hygnstrom 1992). Proportional emergence was calculated as the fraction of the total number of common sunflower seedlings emerged (by 30 DACP, regardless of subsequent mortality status) divided by the number of seeds planted to each microsite. Proportional seedling survival was calculated as the number of survivors (at 30 DACP) divided by the total number of emerged seedlings. ANOVA with the MIXED procedure (Littell et al. 1996) was used to detect differences in emergence and survival among SOC levels, herbicide treatments, and microsites. Actual SOC value from each plot was discarded as a potential covariate because of a lack of statistically significant contribution to either emergence or survival models in any tested form (linear or quadratic alone [or both] or in combination with other variables). Year was treated as a fixed variable.

\section{Seedling Growth-Greenhouse Experiment}

The greenhouse experiment aimed to test the effect of SOC (along the range of concentrations observed in the field) and atrazine on common sunflower seedling fresh biomass. Conducting this experiment in the greenhouse afforded greater control of soil moisture, soil fertility, and temperature.

Common sunflower was used to bioassay the influence of SOC variation on atrazine efficacy. Soil was collected from each of the 12 locations described above plus two other locations (known to have elevated SOC levels) within the same field, for a total of 14 unique sites (six previously classified as low-SOC and eight as high-SOC locations). The 
soil was collected from the top $15 \mathrm{~cm}$ of ridges in mid-April of 1999 before tillage, crop planting, and application of herbicide. Soil was passed through a 4-mm sieve to remove large pieces of plant residue or stones, air-dried in the greenhouse, and stored in large plastic bags until used. Percent soil moisture was determined on the air-dried soil by oven drying a 15-g sample at $110 \mathrm{C}$ to constant weight. SOC was determined for each site by dividing the Walkley-Black soil organic matter test (Anonymous 1998; Walkley and Black 1934) result by 1.724 .

Greenhouse experiments were conducted at the University of Nebraska-Lincoln, and environmental controls were set to simulate early-season (late April-early May) growing conditions in the central and eastern Platte River valley. Nighttime temperature was set to $10 \mathrm{C}$, and daytime temperature was set to $27 \mathrm{C}$. Relative humidity was maintained at a minimum of $40 \%$. To prevent premature floral initiation, the photoperiod was extended to $16 \mathrm{~h}$ with a single $1,000-\mathrm{W}$ metal halide lamp suspended $1 \mathrm{~m}$ above the top of the pots in each block. Incident photosynthetic photon flux density from each lamp was approximately $440 \mu \mathrm{mol}$ $\mathrm{m}^{-2} \mathrm{~s}^{-1}$. Three complete blocks were used in this experiment. Each block was randomly reassigned to a new table weekly, and pots were rerandomized within a block twice weekly to minimize edge, light, and neighbor effects.

The dry-mass equivalent of $650 \mathrm{~g}$ of each soil was placed in $0.95-\mathrm{L}$ styrofoam cups. Inside diameter at the top of a cup was $105 \mathrm{~mm}$. Four 1-cm-diam holes were punched in the sides of each cup near the bottom to allow drainage and subirrigation. Twenty common sunflower seeds, selected and treated as described above to promote germination, were placed on the soil surface and covered by $150 \mathrm{~g}$ dry-weight equivalent of the appropriate soil. Subirrigation, by watering tables, was initiated immediately after planting and allowed to continue overnight. At the end of the irrigation period, soil was assumed to be at 95\% field capacity. To increase uniformity in soil moisture conditions (i.e., prevent unnecessary watering that could leach atrazine from the pots and reduce plant moisture stress that could reduce herbicide uptake), water content was monitored by weighing and maintained at a moisture level above $30 \%$ field capacity. At the beginning of each week, cups were subirrigated overnight. To reduce the effects of differences in soil fertility on seedling growth, fertilizer-supplemented surface irrigation (approximately equal to $2 \mathrm{~cm}$ of rainfall) was applied in the middle of each week.

A no-herbicide treatment and two atrazine treatments equivalent to 0.28 and $0.55 \mathrm{~kg}$ atrazine ai ha ${ }^{-1}$ were applied in 1999. A third herbicide treatment $(1 \times)$ equivalent to the highest recommended rate $\left(1.10 \mathrm{~kg} \mathrm{ha}^{-1}\right)$ was applied when the experiment was repeated in 2000. Atrazine treatments were applied $1 \mathrm{~d}$ after planting (DAP) in a mechanical spray chamber (calibrated to give an output volume equivalent to $375 \mathrm{~L} \mathrm{ha}^{-1}$ using an even, flat-nozzle tip, ${ }^{3}$ a boom travel speed of $3.01 \mathrm{~km} \mathrm{~h}^{-1}$, and application pressure of $276 \mathrm{kPa}$ ). Surface irrigation was applied with a sprinkler head in an amount approximately equal to $1.5 \mathrm{~cm}$ of rainfall 2 DAP. Seedlings were thinned daily to a maximum of four seedlings per pot. Beginning at 14 DAP all newly emerged seedlings were removed regardless of the number of seedlings in the pot.

The experiment in 2000 was conducted as described
TABle 1. Subsample (litterbag) establishment and retrieval, and mean, standard deviation, and range of recovered common sunflower seeds per subsample for each burial treatment (1999 and 2000 data combined). Effect of the no-litterbag treatment on recovery of seeds placed on ridge surface was only tested in 1999.

\begin{tabular}{|c|c|c|c|c|c|}
\hline \multirow[b]{2}{*}{ Treatment } & \multicolumn{2}{|c|}{ Subsamples } & \multicolumn{3}{|c|}{ Recovered seeds } \\
\hline & Established & Retrieved & Mean ${ }^{\mathrm{a}}$ & SD & Range \\
\hline & \multicolumn{2}{|c|}{ - No. } & \multicolumn{3}{|c|}{ — No. per subsample - } \\
\hline Surface & 24 & $20^{\mathrm{b}}$ & 39.2 & 18.9 & $1-50$ \\
\hline Residue & 24 & $18^{\mathrm{b}}$ & 49.9 & 0.3 & $49-50$ \\
\hline Buried & 24 & $18^{\mathrm{b}}$ & 49.9 & 0.3 & $49-50$ \\
\hline No-litterbag & 12 & 12 & 6.4 & 6.3 & $0-23$ \\
\hline
\end{tabular}

a Fifty seeds per litterbag at the beginning of the experiment. Missing litterbags were ignored in calculating the mean number of recovered seeds.

b All missing litterbags from residue and buried treatments were accidentally destroyed by subsoil tillage operations conducted in late December 1998. Missing litterbags from the surface treatment were destroyed by animal activity.

above except that the soil from the 1999 experiment was reused. Before reuse, oat (Avena sativa L.) was used to bioassay soils that had received the highest herbicide rates. No visible signs of atrazine injury were observed after $21 \mathrm{~d}$ of growth. The soil was therefore deemed safe for reuse, mixed with soil from the other herbicide treatments, and mechanically sieved to $2 \mathrm{~mm}$. This soil was used for the $650 \mathrm{~g}$ quantity of soil as described above, and previously unused soil remaining from the 1999 experiment was used for the 150 -g top layer.

Individual aboveground seedling fresh biomass was measured 30 DAP. Dead or necrotic plants were recorded as having a minimum of 0.01 -g fresh biomass. Seedling fresh biomass was calculated as a simple mean across all three blocks in each year. Data were then averaged across years. The GLM procedure in SAS (SAS 1999) was used to test for interactions of SOC with year. One datapoint from the $1 \times$ treatment was excluded from the analysis as an outlier because of a large RStudent value (3.25). Regression models (Freund and Littell 2000) were fit to treatment fresh biomass data as a function of SOC.

\section{Results and Discussion}

\section{Seed Stratification Study}

Only a small fraction of common sunflower seeds dispersed on the ridge surface as a test for a litterbag effect (no-litterbag) was recovered (Table 1). Similarly, mean recovery of seeds from the surface treatment (litterbag) was lower and much more variable (because of predation) than from the residue and buried-seed treatments. These observations suggest that seeds from these surface and no-litterbag treatments were moved from the ridge surface with soil by the effects of erosion (wind and water) or were more obvious to foraging rodents (most likely deer mouse [Peromyscus maniculatus Wagner], but thirteen-lined ground squirrel may have been present in early spring 2000 because of uncharacteristically warm weather). A few seeds from the nolitterbag treatment were also recovered from outside of the rings in which they were originally placed. Residue and buried litterbags were not damaged by granivores, and seed recovery from litterbags was near $100 \%$ in both years (Table 


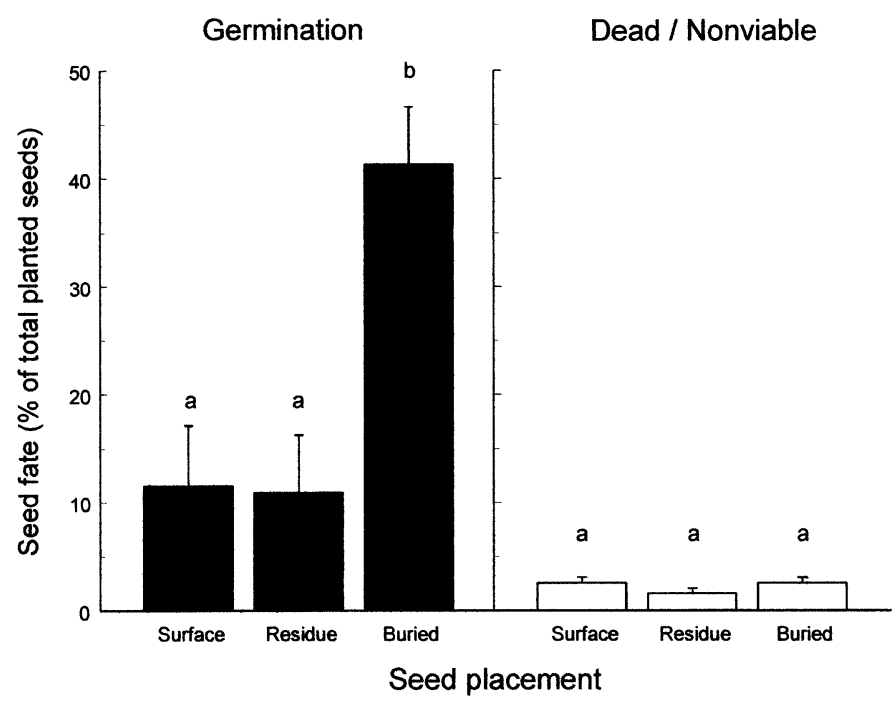

FIGURE 1. Effect of winter burial treatment on common sunflower seed germination and death (1998-1999 and 1999-2000 data combined). The seed fraction not accounted for in the figure was classified as viable by tetrazolium testing. Within germination or dead/nonviable (tetrazolium) tests, treatments with same letter are not different at $\alpha=0.01$, according to a Protected LSD-like test. Error bars are standard error of the mean.

1). Seeds escaping granivory in autumn among crop residues in the furrow because of residue camouflage and seed coat crypsis effects would likely be buried (i.e., protected) in soil by tillage, and planting operations soon after rodent foraging activity increases in the spring.

No interactions of burial treatment, SOC location, or year on the germination of recovered common sunflower seeds occurred, and SOC level did not affect seed germination or mortality (data not shown). Mortality was unaffected by burial treatment among recovered seeds, but germination was strongly affected (Figure 1). Although surface and residue treatments did not differ in proportional germination (both were about 10\%), the buried treatment had greater proportional germination than either of the other two treatments $(P=0.002)$. Buried seeds germinated at a rate four-times greater than seeds in surface or residue treatments. Others have also observed higher proportional germination for common sunflower after burial for a period of months in cold, moist soil, or sand (Teo-Sherrell et al. 1996). This natural process is imitated by laboratory stratification as a seed treatment. The balance of viable seeds was dormant and represented 86,88 , and $56 \%$ of the surface, residue, and buried treatments, respectively.

For buried seeds, the amplitude of temperature cycles is smaller than at the soil surface (Rosenberg et al. 1983) or beneath residues (Gupta et al. 1983; Teasdale and Mohler 1993). Amplitude of the diurnal temperature cycle could be a detectable phenomenon for buried seeds that, along with sufficient moisture, would indicate a superior environmental situation for successful germination and growth. Consequently, percent germination of unburied common sunflower seeds may remain low in the spring after dispersal (on the order of $10 \%$ germination), or until naturally stratified by winter burial under soil.

Fungal hyphae were observed to extend through the litterbags in the residue treatment. Although seed mortality was not greater in the residue treatment than in other treatments, the fungal activity may have contributed to germi- nation inhibition of common sunflower seeds. Gururaj and Mallikarjunaiah (1994) determined that rhizosphere fungal isolates suppressed germination of cultivated common sunflower. Kirkpatrick and Bazzaz (1979) observed suppression of weed seed germination in the presence of seedborne fungi.

Most common sunflower seeds (except for those that fall into soil cracks or are buried by animal activity) overwinter in the residue environment because erosion moves seeds from the ridge to the furrow. Seeds on the surface may be at greater risk of being discovered and eaten by granivores. In the case of the exposed surface treatment, proximity of subsamples to one another may have resulted in increased levels of seed predation within a site because the other surface subsamples were more likely to be noticed and predated if one subsample was discovered. The absence of granivore predation of litterbags in residue treatments in locations where surface litterbags were predated suggests that crop residues offer a degree of protection from granivory.

\section{Emergence and Seedling Survival in the Field}

High- and low-SOC sites within the field were distinct in chemical and physical characteristics that may influence the efficacy of preemergence herbicides (Figure 2). Mean percent SOC for high- and low-SOC plots was 1.8 and $1.1 \%$, respectively. Mean percent clay was 29.3 and $18.2 \%$ for high- and low-SOC plots, respectively. Soil pH, however, overlapped considerably in range between the two site types and had means of 6.7 for high SOC and 6.8 for low SOC.

Overall proportional emergence of common sunflower (defined as cotyledons above soil surface) was lower in 1998 (0.40) than in $1999(0.68)(\mathrm{P}<0.001)$. Different techniques were used to break dormancy in each year; therefore, the year effect is not necessarily attributable to environmental conditions. Because there were no treatment interactions with year, emergence data were combined across years. Emergence was not affected by SOC level as a main-plot effect nor was emergence affected by SOC within herbicide treatment or microsite (data not shown). However, seedling emergence was less for the herbicide-treated than for nontreated ridges (Figure 3). Although effects of atrazine (a photosynthesis inhibitor) would not be obvious until some time after seedling emergence, the lower emergence of herbicidetreated plots was expected because acetochlor (a germination inhibitor) has been observed to have detectable efficacy on common sunflower (Martin et al. 2000).

In untreated (no herbicide) control plots, a greater proportion of common sunflower seeds emerged in ridge than in furrow microsites (Figure 4). The superiority of the ridge microsite for emergence is possibly related to differences in soil bulk density, soil microbial community composition or activity, soil fertility, or other environmental factors such as temperature and moisture dynamics. The average bulk density of ridge microsites in the upper $7.6 \mathrm{~cm}$ (the volume into which seeds were planted) was observed to be $1.17 \mathrm{~g}$ $\mathrm{cm}^{-3}$ compared with $0.96 \mathrm{~g} \mathrm{~cm}^{-3}$ in the furrow. Ridge soils were more consolidated at a shallower depth than furrow microsites because of the lower degree of disturbance that occurs during preparation of the ridge for replanting. The top 5 to $7 \mathrm{~cm}$ of the ridge is typically truncated by rotary tillage and planting, which redistribute soil across the ridge and furrow and covers the accumulated plant residues in the 

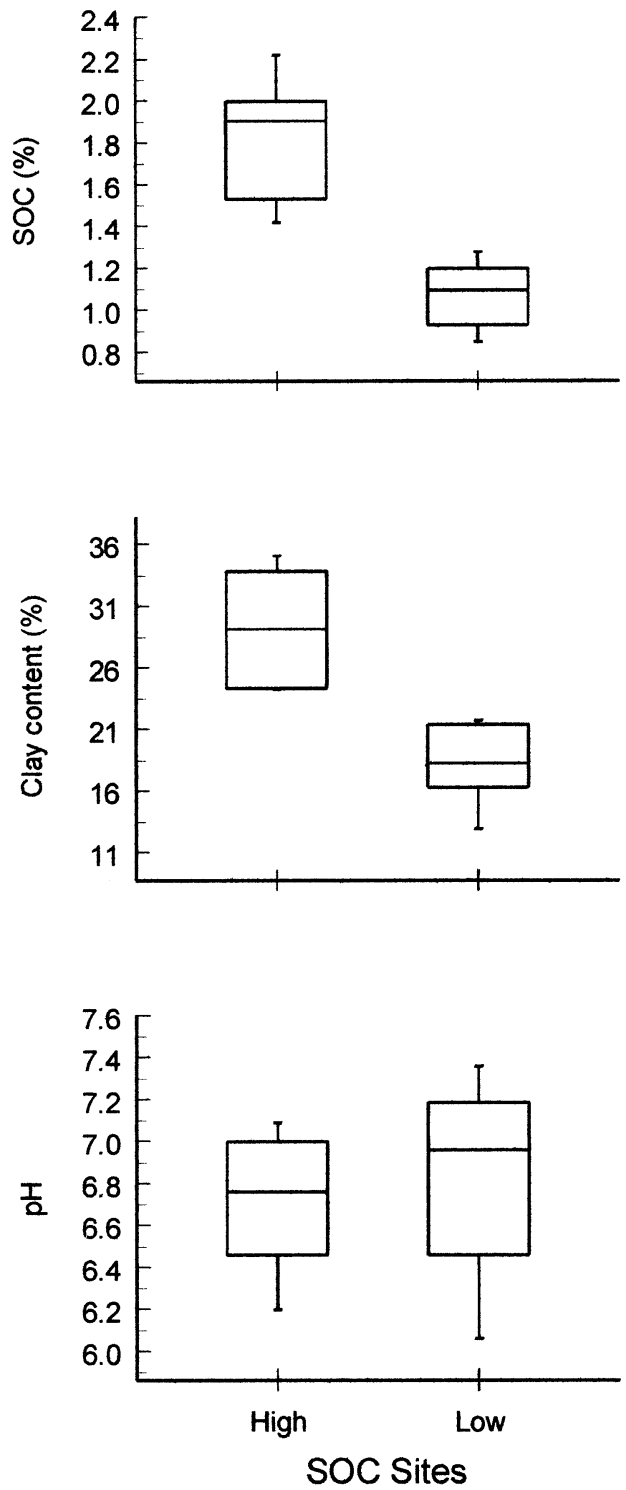

FIgURE 2. Box plots of selected soil characteristics of high- and low-SOC site locations.

furrow. This fairly uniform covering of soil may help explain why soil temperature in the 3- to 7-cm depth range (which includes the depth of common sunflower planting in this experiment) was similar across ridge and furrow microsites after tillage (data not shown). Seeds of common sunflower were therefore planted into rotary-tilled (disturbed) soil and residues in the furrow and rotary-tilled soil that covered relatively undisturbed soil in the ridge. Variability in the height of the equipment as it passes over the field can result in more or less of the soil mixture (including weed seeds from the previous year) remaining on the ridge. Early-season soil microbial activity is likely higher in the furrow than in the ridge microsite because of the decay of the previous year's plant residues. This elevated activity may have created a lesssuitable environment for seed germination and seedling growth (Gururaj and Mallikarjunaiah 1994; Kirkpatrick and Bazzaz 1979). In addition to these factors, soil fertility in the truncated ridge is greater than in the furrow. Because of the permanent location of ridges in the ridge-tillage system and the annual application of starter fertilizer, the P level in

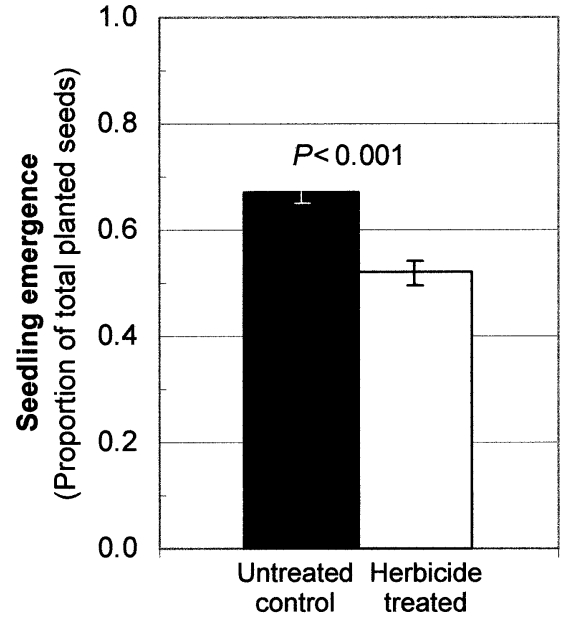

FigURE 3. Effect of herbicide (atrazine + acetochlor) application $(1 / 2 \times$ rate) on common sunflower seedling emergence in the field. Data from 1998 and 1999 are combined. Error bars are standard error of the mean.

the truncated ridge has been enriched by as much as $30 \%$ when compared with soil test levels in the adjacent furrow (J. S. Schepers, personal communication).

No year effect was detected for seedling survival after emergence $(P=0.57)$, and no year by treatment interactions were detected. Therefore, data were combined across years. Analysis of the SOC main-plot effect indicated that common sunflower proportional seedling survival was greater in the high-SOC locations (0.40) than in low-SOC locations $(0.30)(P=0.005$, Figure 5). Seedling survival after emergence was expected to be greater at high SOC levels when plots were treated with acetochlor and atrazine because the bioavailability of these soil-applied herbicides has been shown to decrease with increasing SOC level (Blumhorst et al. 1990; Sheets et al. 1962). Although a numerically greater level of seedling survival in high-SOC locations was evident across years (mean high-SOC seedling survival was $39 \%$ greater than low-SOC survival), statistically significant differences in seedling survival were not detected in the ANOVA for SOC within herbicide-treated ridges (Figure 5). In the absence of herbicide treatment, SOC location did not influence seedling survival in the ridge microsite

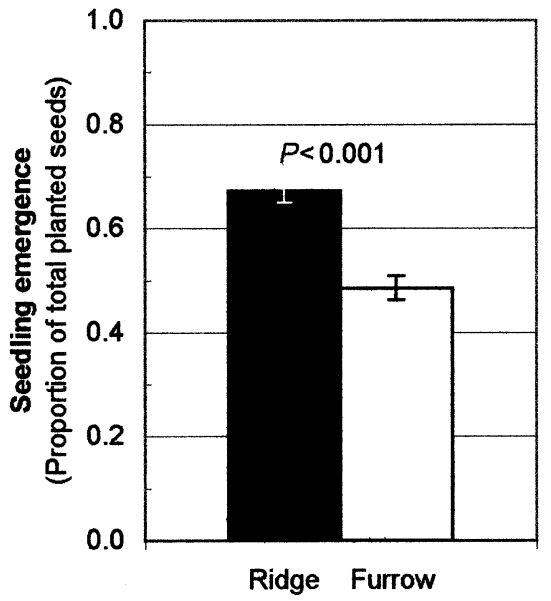

Figure 4. Effect of microsite (ridge vs. furrow) on untreated (no herbicide) common sunflower emergence in the field. Data from 1998 and 1999 are combined. Error bars are standard error of the mean. 


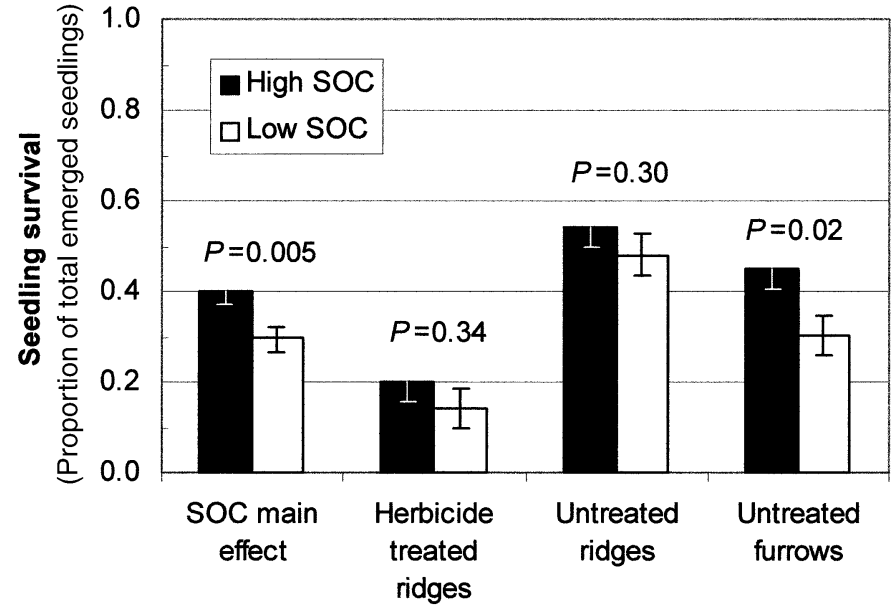

FIGURE 5. Effect of SOC on common sunflower seedling survival in the field as a main-plot effect, in herbicide (atrazine + acetochlor)-treated ridges, in untreated ridges, and in untreated furrows. Data from 1998 and 1999 are combined. Error bars are standard error of the mean.

(although survival in high-SOC locations was again numerically greater than low-SOC locations), whereas furrow seedlings demonstrated increased survival in high-SOC locations $(P=0.02$, Figure 5$)$. In the absence of herbicide, a greater proportion of seedlings survived in the ridge than in the furrow $(\mathrm{P}<0.001$, Figure 6$)$.

\section{Seedling Growth in the Greenhouse}

The results of the greenhouse experiment were combined across years because of lack of treatment by year interactions. Common sunflower seedling fresh biomass increased with increasing SOC percent in the $1 / 4 \times(\mathrm{P}=0.07), 1 / 2 \times(\mathrm{P}$ $=0.01)$, and $1 \times(P=0.04)$ treatments (Figure 7$)$. Note that the datapoint corresponding to $1.42 \%$ SOC was considered an outlier in the $1 \times$ treatment because of a large RStudent value (3.25). The outlier value was therefore excluded from the regression model. In all three atrazine treatments, the slope was positive and predicts a relative increase in atrazine-treated common sunflower seedling fresh biomass of 13 to $24 \%$ per $1 \%$ increase in SOC. Often one of the four seedlings in herbicide-treated pots would grow with little to no observable injury, whereas the other three seedlings were small or necrotic. Such management "escapes" more often occurred in pots containing high-SOC soil than in pots with low-SOC soil (data not shown). If this were to occur in the field, the large escaped seedlings potentially could have survived to compete with the crop and reproduce. These results suggest that uniform herbicidal management of fields with variable SOC levels may leave high-SOC areas a relatively more favorable habitat or "refuge" for weed species with greater tolerance to atrazine.

A feature of the ridge-tillage system is that most weed seeds and spilled crop seeds and ears fell into the furrow or are moved from the crop row when the ridge is truncated during or immediately before planting. The majority of dispersed weed seeds from the previous harvest season are likely deposited in the furrow among or below residues. Our data indicate that seeds covered by residues (but not covered by soil) have lower germination than seeds buried $5 \mathrm{~cm}$ in soil. Consequently, a larger fraction of surviving seeds may ger-

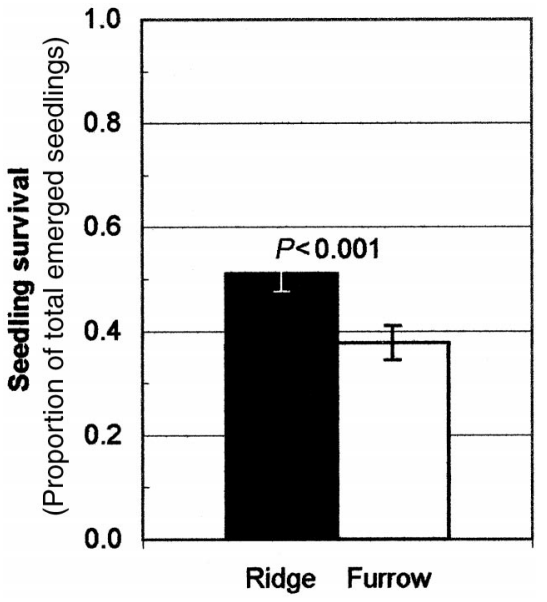

FIGURE 6. Effect of microsite (ridge vs. furrow) on common sunflower seedling survival in the absence of herbicide in the field. Data from 1998 and 1999 are combined. Error bars are standard error of the mean.

minate in the spring after burial by rotary tillage, cultivation, and ridging practices. Our data indicate no effect of SOC level on germination or seed survival of common sunflower after a single winter of stratification.

We highlight three important influences of environment on the fate of common sunflower seedlings: (1) proportional survival of seedlings (SOC main-plot effect) and seedling fresh biomass (greenhouse studies) were greater in high-SOC locations, (2) seedling survival was greater in untreated highSOC furrow environments than in untreated low-SOC furrows, and (3) in the absence of soil-applied herbicide, seedling emergence and survival were greater in the ridge microsite than in the furrow microsite. These observed differences suggest that common sunflower may experience

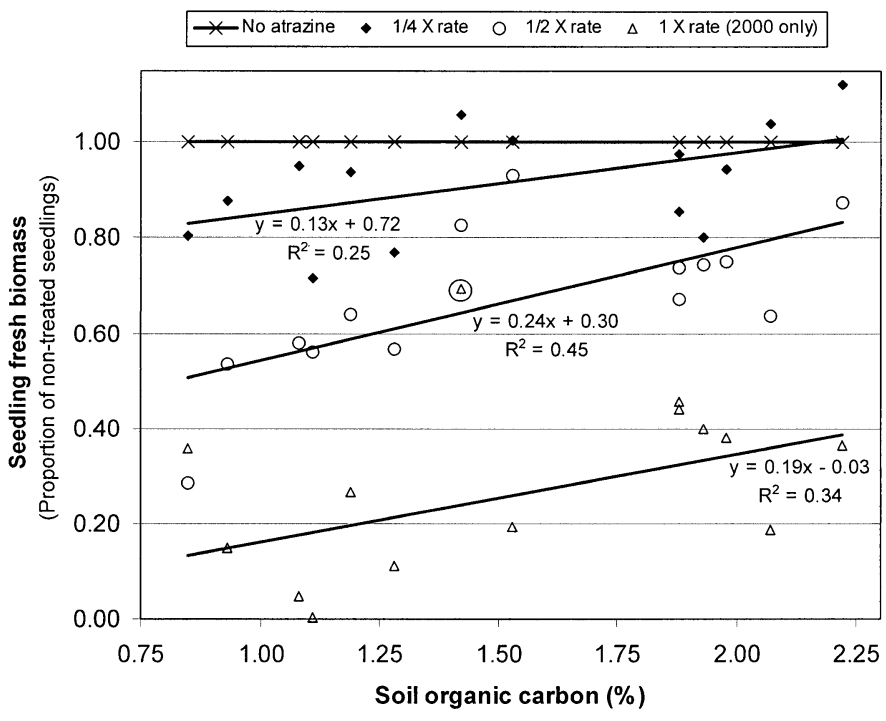

Figure 7. Common sunflower seedling fresh biomass response to soil-applied atrazine in field soil across a range of natural soil organic carbon (SOC) concentrations. Soil was collected from 14 locations within the same 64-ha field for this greenhouse experiment. Simple (not least squares) means are plotted as a fraction of the no-herbicide seedling fresh biomass for each soil collection site. Data from 1999 and 2000 are combined. Note that two collection sites had SOC levels near $1.9 \%$ and that the circled value in the $1 \times$ rate treatment was excluded from statistical analysis as an outlier. (Regression models were significant at $\mathrm{P}=0.07,0.01$, and 0.04 for $1 / 4 \times, 1 / 2 \times$, and $1 \times$ rates, respectively.) 
increased likelihood of escaping preemergence herbicide (atrazine is strongly sorped by SOC) management in highSOC environments. Similarly, untreated common sunflower may be more likely to survive in the furrow environment in high- than in low-SOC locations. Common sunflower seedlings at the edge of the cultivator swath (which is typically near the edge of the preemergence herbicide band treatment) have occasionally been observed to survive cultivation and ridging operations (unpublished data). We believe that the observed greater common sunflower survival and seedling fresh biomass in high-SOC soils are important to the population ecology of common sunflower in intensively managed corn production systems. Therefore, subfield areas with high-SOC soils that are located in fields under uniform chemical management may constitute a safer habitat type for common sunflower because seedlings might be more likely to survive preemergence herbicide treatments. For species with high fecundity and long seed bank life, such as common sunflower, a small number of survivors may replenish the soil seed bank for many years. Altered or additional IWM tactics may be required for common sunflower management in high-SOC environments to offset the greater potential for seedling survival — especially where managers are already using maximum recommended herbicide rates.

\section{Sources of Materials}

${ }^{1}$ Giberellic Acid, GA 3 , Product no. G-7645, Sigma-Aldrich Corp., 3050 Spruce Street, St. Louis, MO 63103.

2 Phosphate buffered saline, $\mathrm{pH}$ 7.4, Product no. P-3813, Sigma-Aldrich Corp., 3050 Spruce Street, St. Louis, MO 63103.

3 TeeJet ${ }^{\circledR} 8002 \mathrm{E}$, even flat spray tip, TeeJet ${ }^{\circledR}$ Midwest, 3062 104th Street, Urbandale, IA 50322.

\section{Acknowledgments}

We acknowledge and thank David Stoltenberg and two other thoughtful, yet anonymous, reviewers. Their comments helped to improve and focus this manuscript. We also express our gratitude to Mr. Paul Gangwish, farmer/cooperator. This research was funded in part by the USDA National Research Initiative Competitive Grants Program.

\section{Literature Cited}

Andreasen, C., J. C. Streibig, and H. Haas. 1991. Soil properties affecting the distribution of 37 weed species in Danish fields. Weed Res. 31: $181-187$.

Anonymous. 1998. Recommended Chemical Soil Test Procedures for the North Central Region. Publication No. 221 (revised). Pp. 55-56.

Anonymous. 2000. Tetrazolium Testing Handbook, Revised. Tetrazolium Testing Committee of the Association of Official Seed Analysts. J. Peters, ed. Lincoln, NE: Association of Official Seed Analysts.

Austin, M. P. and B. O. Austin. 1980. Behaviour of experimental plant communities along a nutrient gradient. J. Ecol. 68:891-918.

Bauer, T. A. and D. A. Mortensen. 1992. A comparison of economic and economic optimum thresholds for two annual weeds in soybeans. Weed Technol. 6:228-235.

Blumhorst, M. R., J. B. Weber, and L. R. Swain. 1990. Efficacy of selected herbicides as influenced by soil properties. Weed Technol. 4:279-283.

Burton, M. G. 2000. Effects of Soil and Landscape Characteristics on the Population Dynamics of Wild Helianthus annuus L. Ph.D dissertation. University of Nebraska, Lincoln, NE. Pp. 9-50, 130-181.

Burton, M. G. and D. A. Mortensen. 2002. Contribution of seed re-dispersal in Helianthus annuus L. patch persistence. Proc. South. Weed Sci. Soc. 55:186-187.

Cambardella, C. A., T. B. Moorman, J. M. Novak, T. B. Parkin, D. L. Karlen, R. F. Turco, and A. E. Konopka. 1994. Field-scale variability of soil properties in Central Iowa soils. Soil Sci. Soc. Am. J. 58:15011511.

Cardina, J., E. Regnier, and D. Sparrow. 1995. Velvetleaf (Abutilon theophrasti) competition and economic thresholds in conventional- and no-tillage corn (Zea mays). Weed Sci. 42:81-87.

Coffin, D. P. and W. K. Lauenroth. 1994. Successional dynamics of a semiarid grassland: effects of soil texture and disturbance size. Vegetatio 110:67-82.

Cousens, R. and M. Mortimer. 1995. Dynamics of Weed Populations. Port Chester, NY: Cambridge University Press. Pp. 18-19.

Cousens, R. D. and J. L. Woodcock. 1997. Spacial dynamics of weeds: an overview. Pages 613-618 in Proceedings of the Brighton Crop Protection Conference-Weeds. Farnham, UK: British Crop Protection Council.

Dale, H. M. 1964. Influence of soil on weed vegetation on a drained river millpond. Can. J. Bot. 42:823-830.

Dale, M.R.T., A. G. Thomas, and E. A. John. 1992. Environmental factors including management practices as correlates of weed community composition in spring seeded crops. Can. J. Bot. 70:1931-1939.

Dieleman, J. A., D. A. Mortensen, D. D. Buhler, C. A. Cambardella, and T. B. Moorman. 2000a. Identifying associations among site properties and weed species abundance. I. Multivariate analysis. Weed Sci. 48: 567-575.

Dieleman, J. A., D. A. Mortensen, D. D. Buhler, and R. B. Ferguson. 2000b. Identifying associations among site properties and weed species abundance. II. Hypothesis generation. Weed Sci. 48:576-587.

Doyle, C. J. 1991. Mathematical models in weed management. Crop Prot. 10:432-444.

Fernandez-Quintanilla, C., L. Navarrette, C. Torner, and J. L. Andujar. 1987. Influence of herbicide treatments on the population dynamics of Avena sterilis ssp. ludoviciana (Durieu) Nyman in winter wheat crops. Weed Res. 27:375-383.

Forcella, F. and M. J. Lindstrom. 1988a. Movement and germination of weed seeds in ridge-till crop production systems. Weed Sci. 36:56-59.

Forcella, F. and M. J. Lindstrom. 1988b. Weed seed populations in ridge and conventional tillage. Weed Sci. 36:500-503.

Freund, R. J. and R. C. Littell. 2000. SAS ${ }^{\circledR}$ System for Regression. 3rd ed. Cary, NC: Statistical Analysis Systems Institute.

Gonzalez-Andujar, J. L. and C. Fernandez-Quintanilla. 1991. Modelling the population dynamics of Avena sterilis under dry-land cereal cropping systems. J. Appl. Ecol. 28:16-27.

Gupta, S. C., W. E. Larson, and D. R. Linden. 1983. Tillage and surface residue effects on soil upper boundary temperatures. Soil Sci. Soc. Am. J. 47:1212-1218.

Gururaj, R. and R. R. Mallikarjunaiah. 1994. Interaction effect of Azotobacter and phosphate-solubilizing fungi on seed germination and seedling growth of sunflower. Helia 17:33-40.

Harper, J. L. 1977. Population Biology of Plants. New York: Academic. $892 \mathrm{p}$.

Hartgerink, A. P. and F. A. Bazzaz. 1984. Seedling-scale environmental heterogeneity influences individual fitness and population structure. Ecology 65:198-206.

Hoveland, C. S., G. A. Buchanan, and M. C. Harris. 1976. Response of weeds to soil phosphorus and potassium. Weed Sci. 24:194-201.

Johnson, G. A., M. G. Krusemark, and J. Bell. 1999. Using a GIS to study the interaction of terrain attributes and weed occurrence. Weed Sci. Soc. Am. Abstr. 39:333.

Kirkpatrick, B. L. and F. A. Bazzaz. 1979. Influence of certain fungi on seed germination and seedling survival of four colonizing annuals. J. Appl. Ecol. 16:515-527.

Klein, R. N., G. A. Wicks, and R. G. Wilson. 1996. Ridge-till, an integrated weed management system. Weed Sci. 44:417-422.

Lindquist, J. L., B. D. Maxwell, D. D. Buhler, and J. L. Gunsolus. 1995. Velvetleaf (Abutilon theophrasti) recruitment, survival, seed production, and interference in soybean (Glycine max). Weed Sci. 43:226-232.

Littell, R. C., G. A. Milliken, W. W. Stroup, and R. D. Wolfinger. 1996. SAS System for Mixed Models. Cary, NC: Statistical Analysis Systems Institute.

Maguire, J. D. and A. Overland. 1959. Laboratory Germination of Weedy and Native Plants. Pullman, WA: Washington Agricultural Experiment Station Bulletin. No. 349.15 p.

Martin, A. R., F. W. Roeth, R. G. Wilson, G. A. Wicks, R. N. Klein, D. J. Lyon, and S. Z. Knezevic. 2000. 2000 Guide for Weed Management in Nebraska. Lincoln, NE: Nebraska Cooperative Extension Service EC 00-130-D.

Maxwell, B. D. and C. Ghersa. 1992. The influence of weed seed dispersion 
versus the effect of competition on crop yield. Weed Technol. 6:196204.

Medlin, C. R., D. R. Shaw, M. S. Cox, P. D. Gerard, M. J. Abshire, and M. C. Wardlaw, III. 2001. Using soil parameters to predict weed infestations in soybean. Weed Sci. 49:367-374.

Mortensen, D. A., L. Bastiaans, and M. Sattin. 2000. The role of ecology in the development of weed management systems: an outlook. Weed Res. 40:49-62.

Mueller-Dombois, D. and H. P. Sims. 1966. Response of three grasses to two soils and a water table depth gradient. Ecology 47:644-648.

Naylor, R.E.L. 1972. Aspects of the population dynamics of the weed Alopecurus myosuroides Huds. in winter cereal crops. J. Appl. Ecol. 9: 127-139.

Novak, J. M., T. B. Moorman, and C. A. Cambardella. 1997. Atrazine sorption at the field scale in relation to soils and landscape position. J. Environ. Qual. 26:1271-1277.

Pickett, S.T.A. and F. A. Bazzaz, 1976. Divergence of two co-occurring successional annuals on a soil moisture gradient. Ecology 57:169-176.

Rew, L. J. and G. W. Cussans. 1997. Horizontal movement of seeds following tine and plough cultivation: implications for spatial dynamics of weed infestations. Weed Res. 37:247-256.

Rosenberg, N. J., B. L. Blad, and S. B. Verma. 1983. Microclimate: The Biological Environment. 2nd ed. New York: J. Wiley. Pp. 99-100.

[SAS] Statistical Analysis Systems. 1999. SAS/STAT User's Guide. Version 8. Cary, NC: Statistical Analysis Systems Institute.

Sheets, T. J., A. S. Crafts, and H. R. Drever. 1962. Influence of soil prop- erties on the phytotoxicities of the $s$-triazine herbicides. J. Agric. Food Chem. 10:458-462.

Teasdale, J. R. and C. L. Mohler. 1993. Light transmittance, soil temperature, and soil moisture under residue of hairy vetch and rye. Agron. J. 85:673-680.

Teo-Sherrell, C.P.A., D. A. Mortensen, and M. E. Keaton. 1996. Fates of weed seeds in soil: a seeded core method of study. J. Appl. Ecol. 33: $1107-1113$.

Tyler, G. 1996. Cover distributions of vascular plants in relation to soil chemistry and soil depth in a granite rock ecosystem. Vegetatio 127: 215-223.

Varvel, G. E., M. R. Schlemmer, and J. S. Schepers. 1999. Relationship between spectral data from an aerial image and soil organic matter and phosphorus levels. Precis. Agric. 1:291-300.

Virchow, D. and S. E. Hygnstrom. 1992. The Thirteen-Lined Ground Squirrel: Controlling Damage. NebGuide G92-1110-A. Lincoln, NE: Nebraska Cooperative Extension Service, University of Nebraska.

Walkley, A. and I. A. Black. 1934. An examination of Degtjareff method for determining soil organic matter and a proposed modification of the chromic acid titration method. Soil Sci. 37:29-37.

Wicks, G. A. and B. R. Somerhalder. 1971. Effect of seedbed preparation for corn on distribution of weed seed. Weed Sci. 19:666-669.

Williams, M. M., II, D. A. Mortensen, A. R. Martin, and D. B. Marx. 2001. Relevance of sub-field soil heterogeneity on herbicide-mediated crop and weed fitness. Weed Sci. 49:798-805.

Received July 27, 2001, and approved March 8, 2004. 